\title{
NASA'S NUCLEAR THERMAL PROPULSION PROJECT
}

\author{
PRESENTED AT
}

NUCLEAR AND EMERGING TECHNOLOGIES FOR SPACE (NETS) 2015

FEBRUARY 23, 2015

Mike Houts

Sonny Mitchell

Tony Kim

Stan Borowski

Kevin Power

John Scott

Anthony Belvin

Steve Clement 


\section{Nuclear Thermal Propulsion (NTP)}
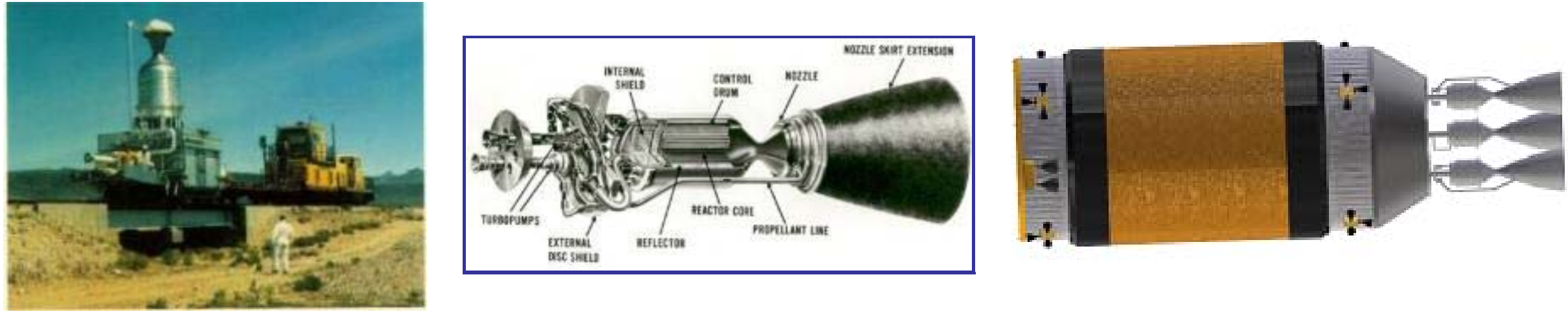

- Nuclear thermal propulsion (NTP) is a fundamentally new capability

- Energy comes from fission, not chemical reactions

- Virtually unlimited energy density

- Initial systems will have specific impulses roughly twice that of the best chemical systems

- Reduced propellant (launch) requirements, reduced trip time

- Beneficial to near-term/far-term missions currently under consideration

- Advanced nuclear propulsion systems could have extremely high performance and unique capabilities

- The goal of the NTP project is to establish adequate confidence in the affordability and viability of NTP such that NTP is seriously considered as a baseline technology for future NASA human exploration missions 


\section{Nuclear Thermal Propulsion (NTP) Organizational Structure}

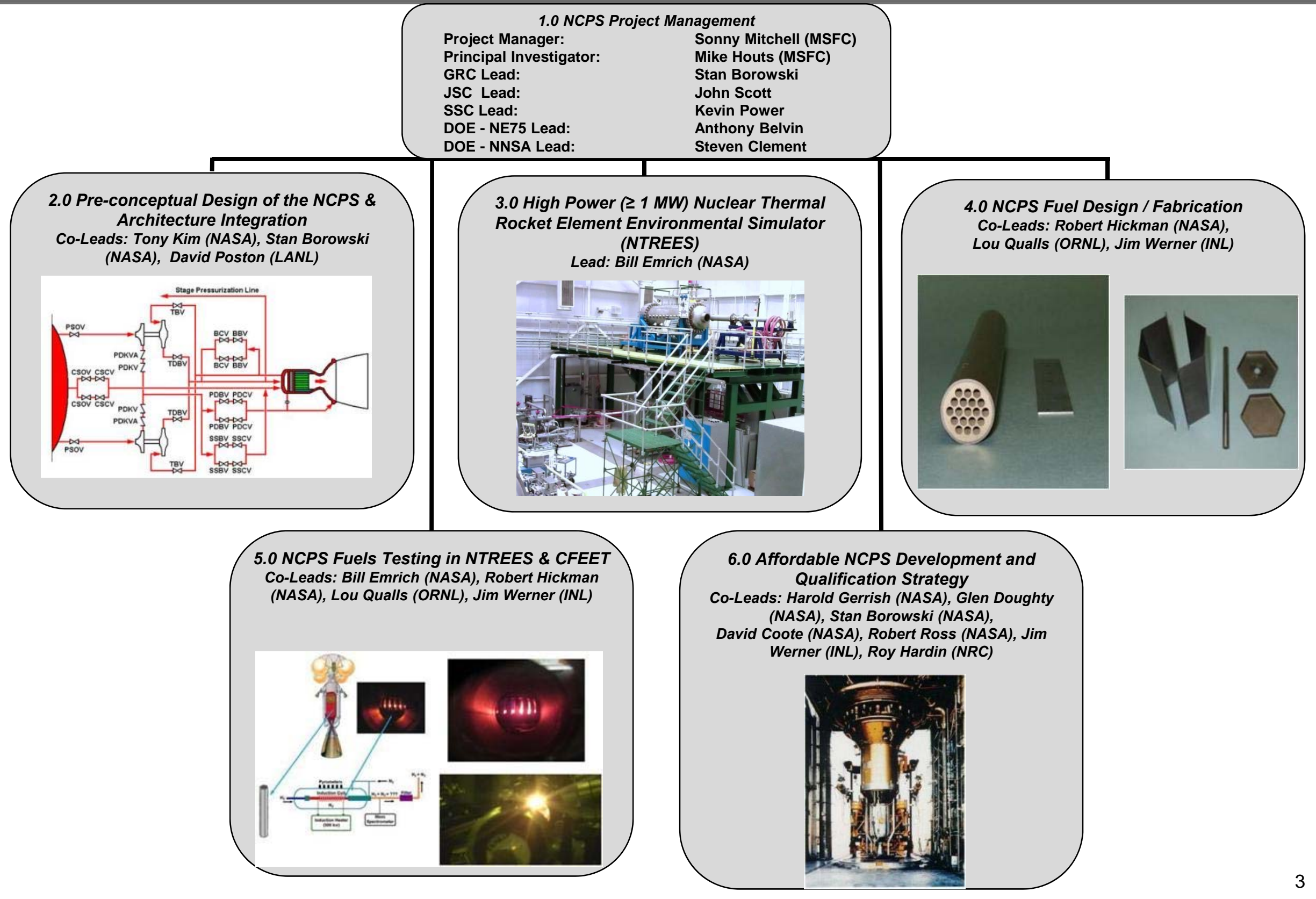




\section{NTP Project FY 15 Milestones}

1. Independent Review Panel provides recommendations on down selection of leader and follower fuel element types (Cermet vs. graphite composite) - Completed 2/15/15

2. Complete initial NTREES testing of $\sim 16$ " cermet fuel element with prototypic depleted uranium loading (Due 3/15/2015)

3. Complete initial NTREES testing of $\sim 16$ " coated graphite composite fuel element with prototypic depleted uranium loading (Due 4/28/2015)

4. Independent Review Panel completes initial assessment of ground test facilities and provides recommendations on facilities and test approach (Due 9/15/2015). 


\section{Recommendations from Independent Review Panel (IRP)}

Given four key assumptions, the Independent Review Panel (IRP) recommended Graphite Composite fuel as the leader technology and Cermet fuel as the follower technology.

Under "Better Approaches and Alternatives," the IRP suggested that the need and timing for an early flight demonstration should be reassessed. In addition, fully developed DDT\&E plans should be generated.

Under "Better Approaches and Alternatives" the IRP also noted the need to evaluate the safety and mission performance achievable for both graphite composite and cermet fuel using low-enriched uranium (LEU). 


\section{Short, 7 Channel $\mathrm{W}_{\mathrm{UUO}}$ Element Fabricated and Tested in Compact Fuel Element Environmental Tester (CFEET)}

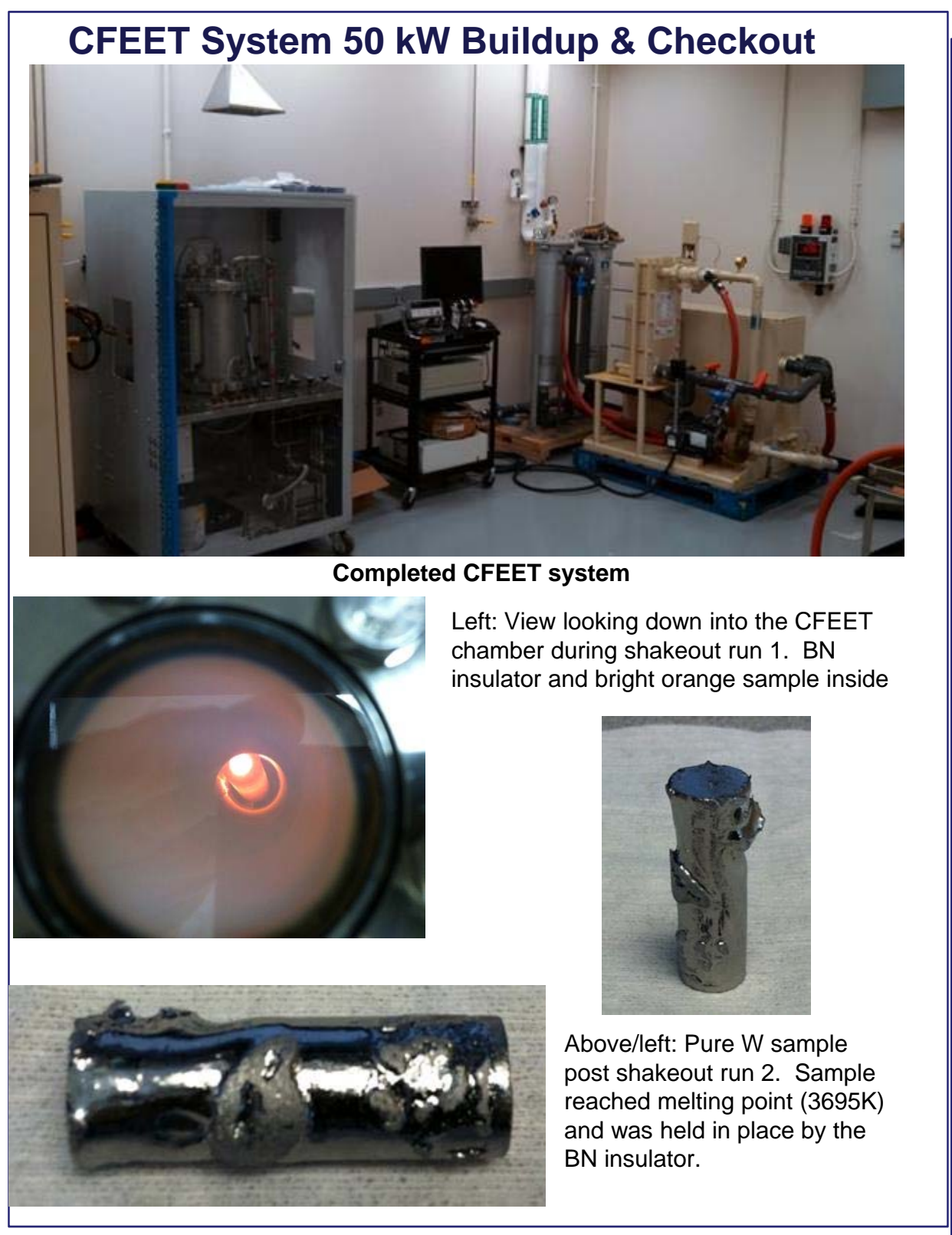

Initial Testing of Short $\mathrm{W} / \mathrm{UO}_{2}$ Element 


\section{CERMET W Powder Coated $\mathrm{UO}_{2}$ HIP Sample}

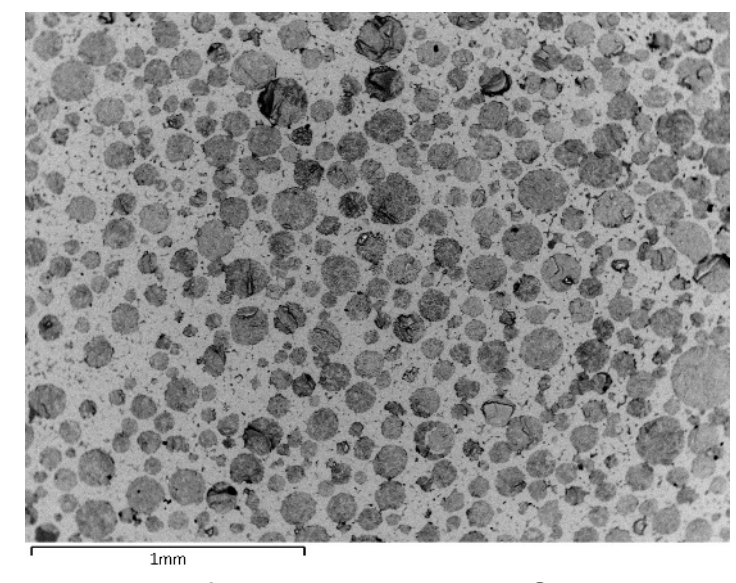

Micrograph of W powder coated $\mathrm{UO}_{2} \mathrm{HIP}$ sample showing improved distribution of $\mathrm{UO}_{2}$ (dark phase) spheres in the $\mathrm{W}$ (light phase)matrix.

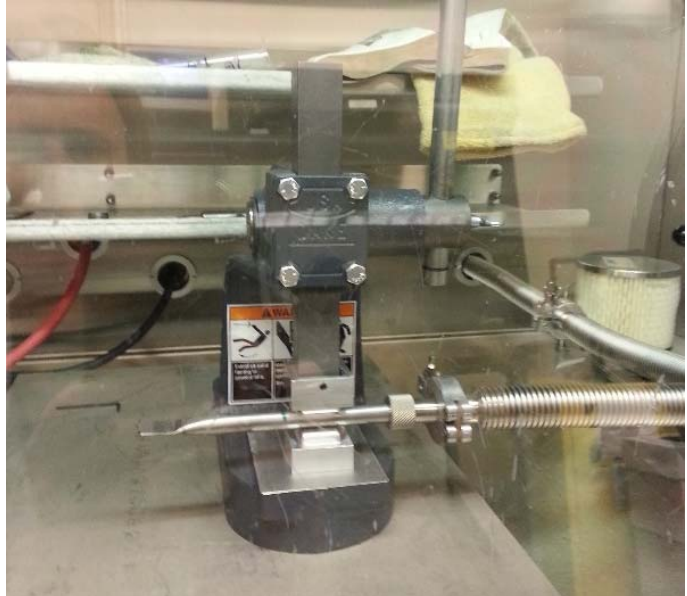

Crimp and sealing of $\mathrm{W}$ powder coated $\mathrm{UO}_{2}$ sample in glovebox

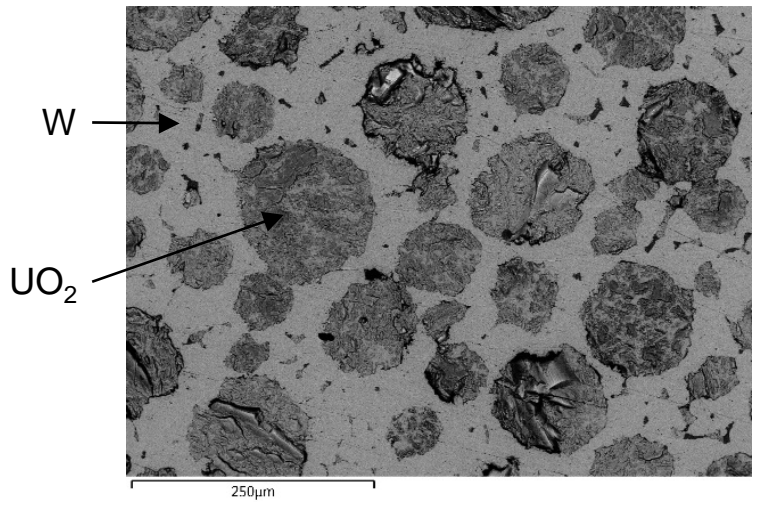

$250 \mu$

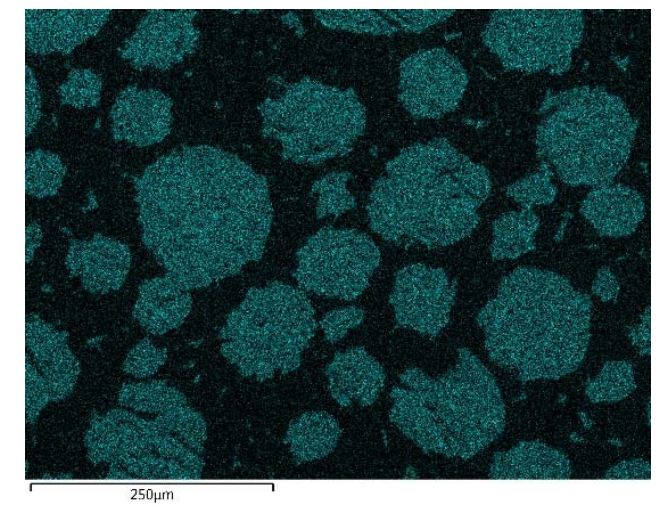

Uranium Phase (blue)

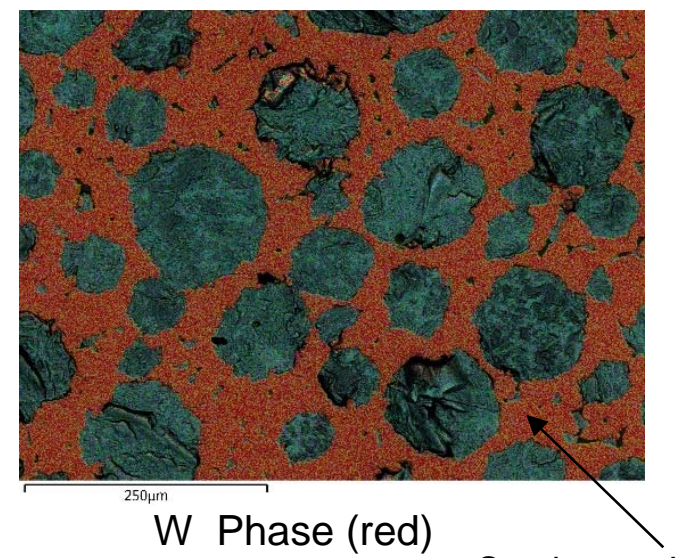

Continuous W Matrix

SEM phase map of $\mathrm{W}$ powder coated $\mathrm{UO}_{2}$ HIP sample showing improved distribution of $\mathrm{UO}_{2}$ (blue phase) spheres in the $\mathrm{W}$ (red phase) matrix. 


\section{CERMET W-UO ${ }_{2}$ 6" 19-Hole Fuel Sample}
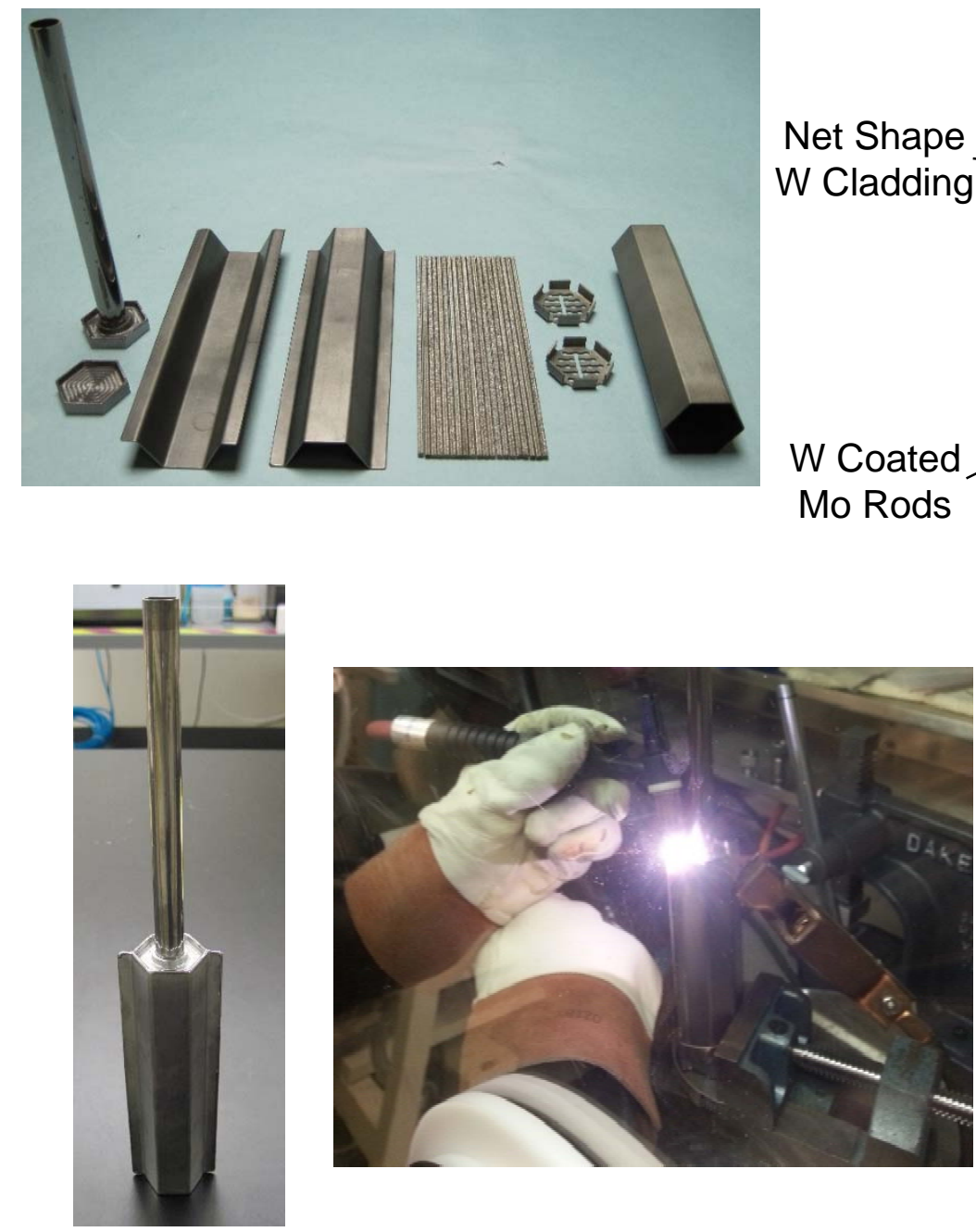

Images showing the 6" long 19-hole W-UO ${ }_{2} \mathrm{HIP}$ can assembly prior to, during, and after welding

Mo Rods
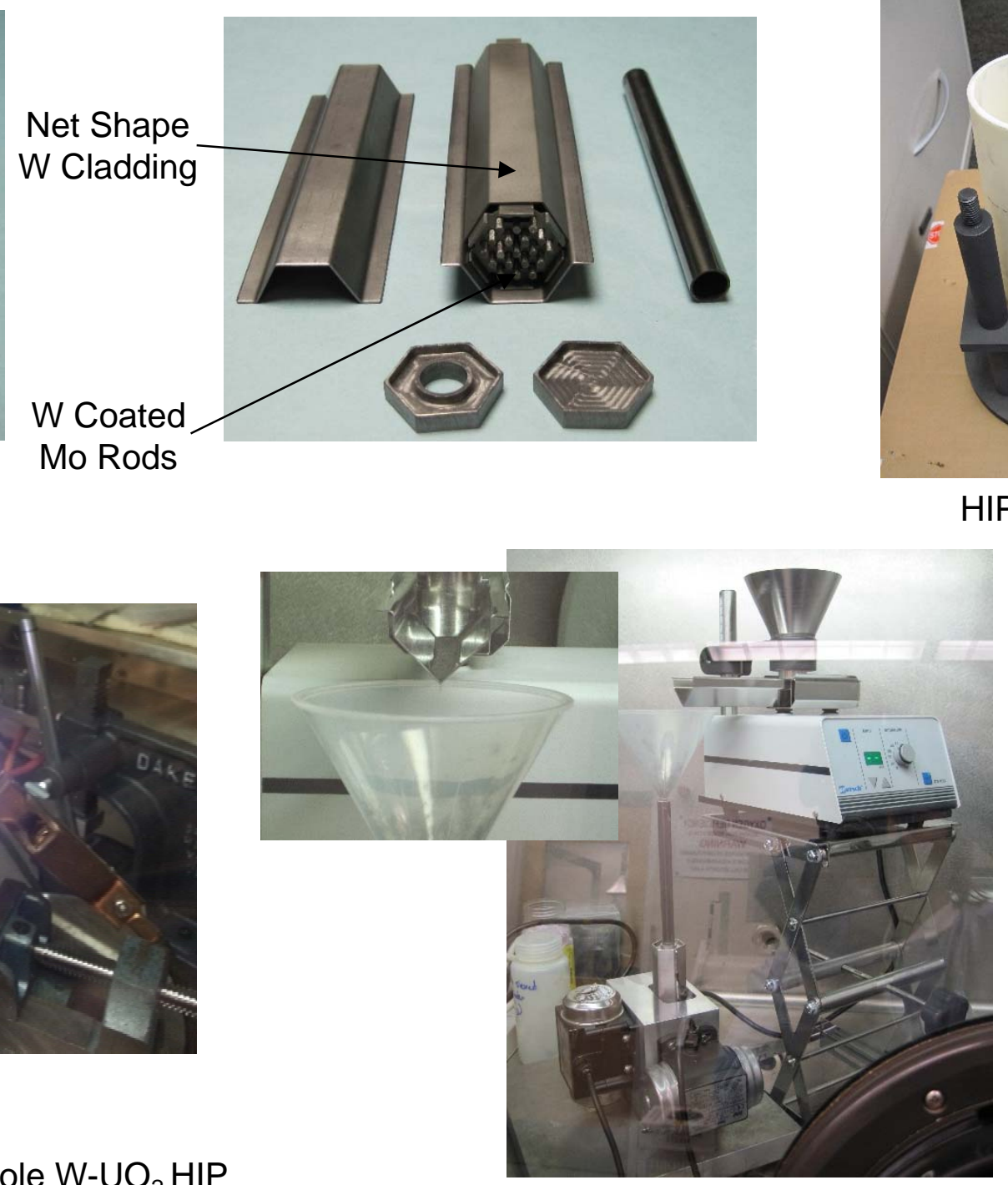

19 Hole HIP can $\mathrm{W}-\mathrm{UO}_{2}$ powder fill in glovebox

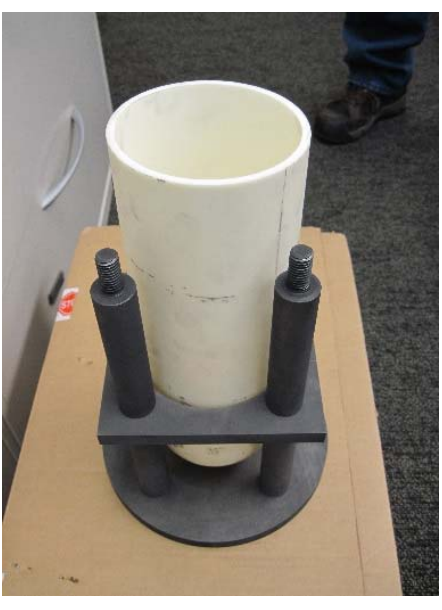

HIP Tooling 


\section{NTP CERMET Fuel Element Development}

- Completed fabrication, assembly, welding of two 4.5" HIP cans for pure W samples (one with internal cladding/one without)

- Change to 4.5" from 6" was due to availability of the $\mathrm{W}$ cladding

- Filled two HIP cans with pure W powder

- Achieved $\sim 65 \%$ packing density in each can

- Completed HIP cycle for the pure W sample with internal cladding

- Sample appears to be near full consolidation without can failure

- Pure W samples will be used to evaluate shrinkage, etching, and machining

- Fabricating full length HIP can for pure W sample prior to fab/HIP of full length $\mathrm{UO}_{2} \mathrm{FE}$

- Will follow with NTREES sample fabrication
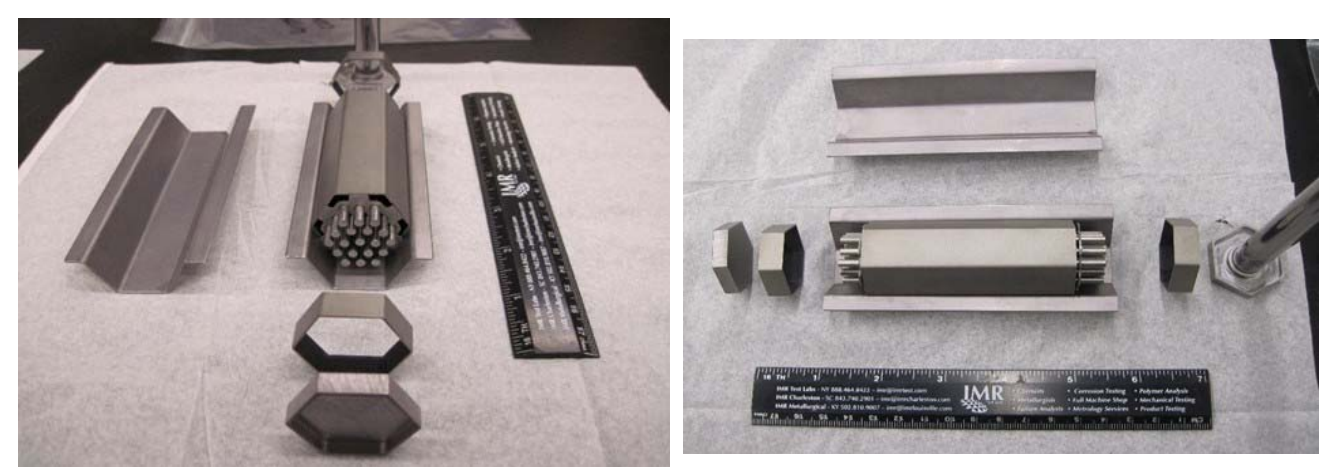

HIP can assembly for pure W samples prior to welding

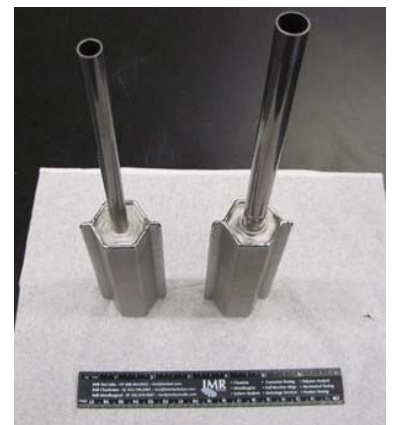

Welded HIP can assemblies for pure W samples
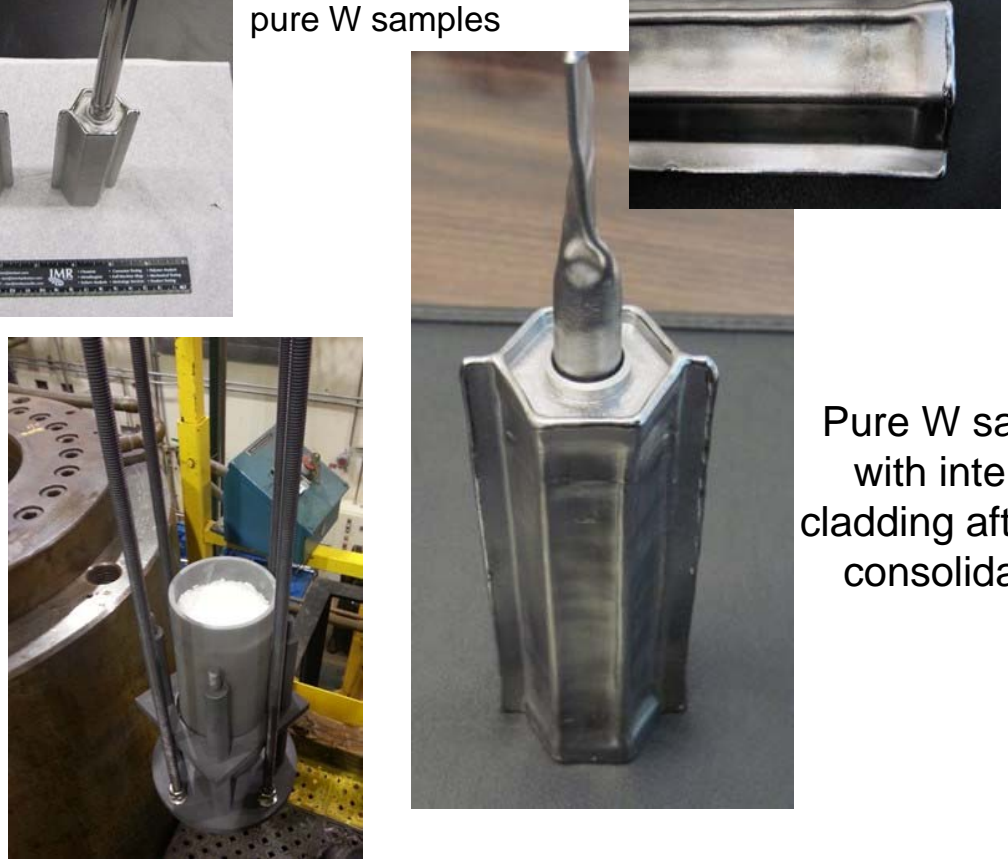

Pure W sample with internal cladding after HIP consolidation

Pure W sample being loaded into HIP vessel for consolidation. Sample is buried in Al2O3 grit; Provides structural support 


\section{Compact Fuel Element Environmental Test (CFEET)}

System and Etch System Upgrades
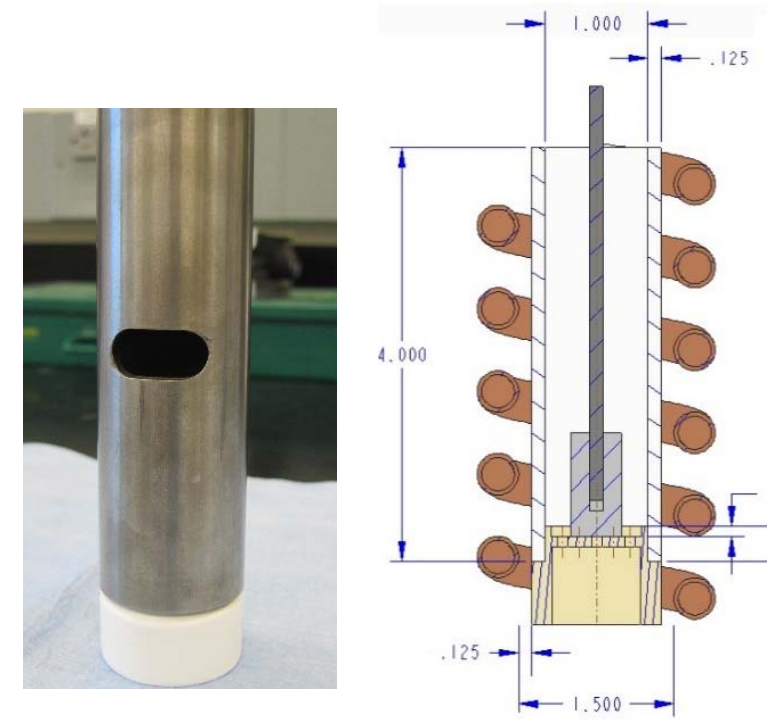

W susceptor and BN Pedestal
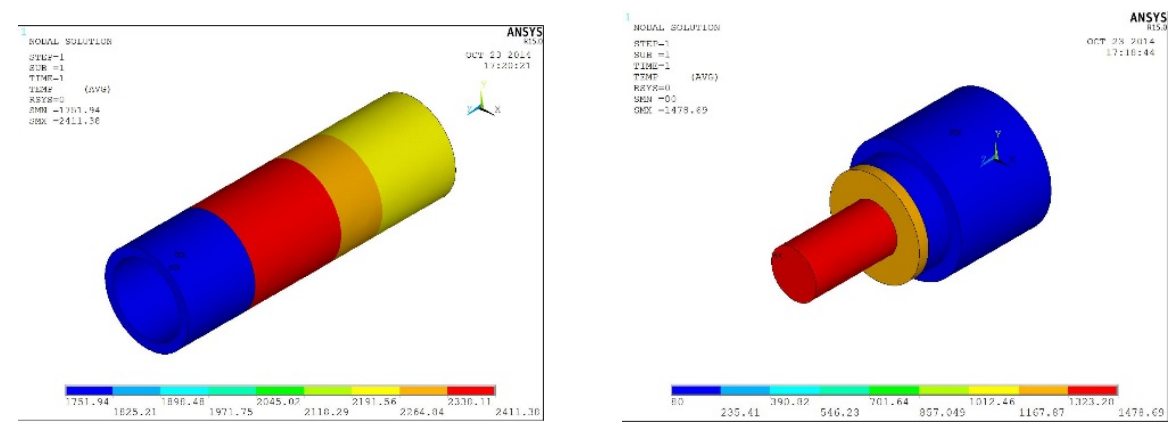

Thermal Model of W susceptor and BN Pedestal
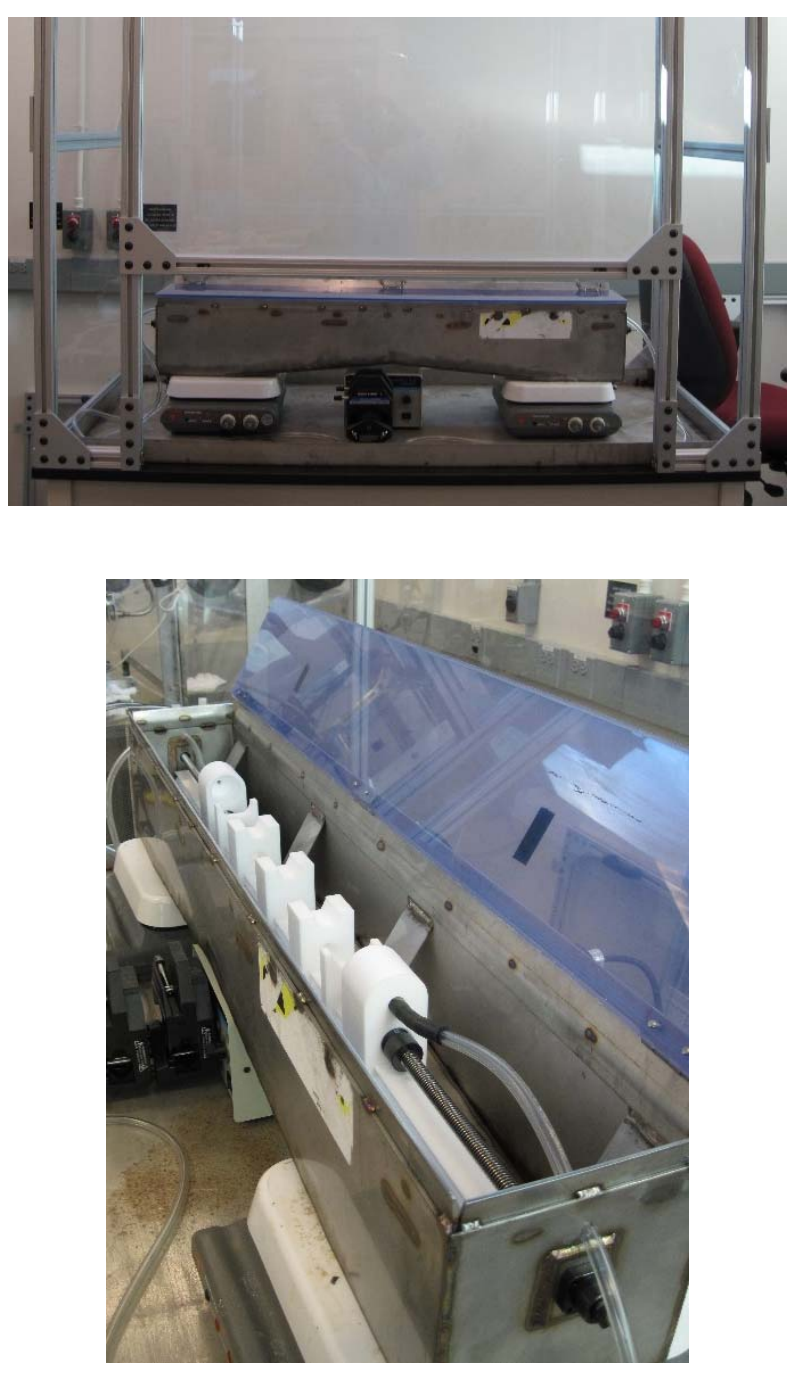

Full Length Fuel Element Etch System 


\section{Other Milestones: ORNL Graphite Composite Development}

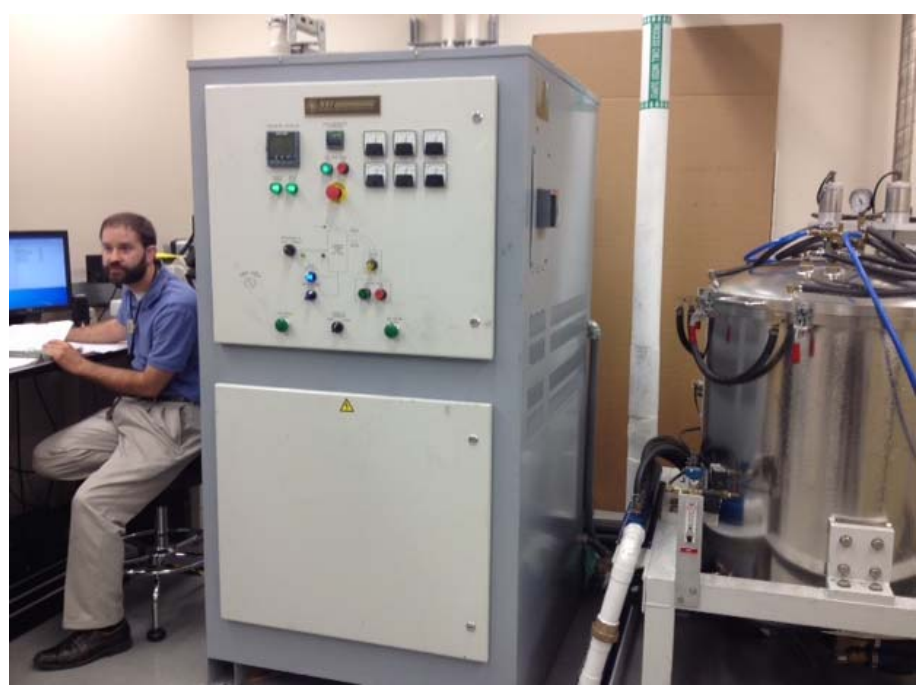

MSFC High Temperature Furnace

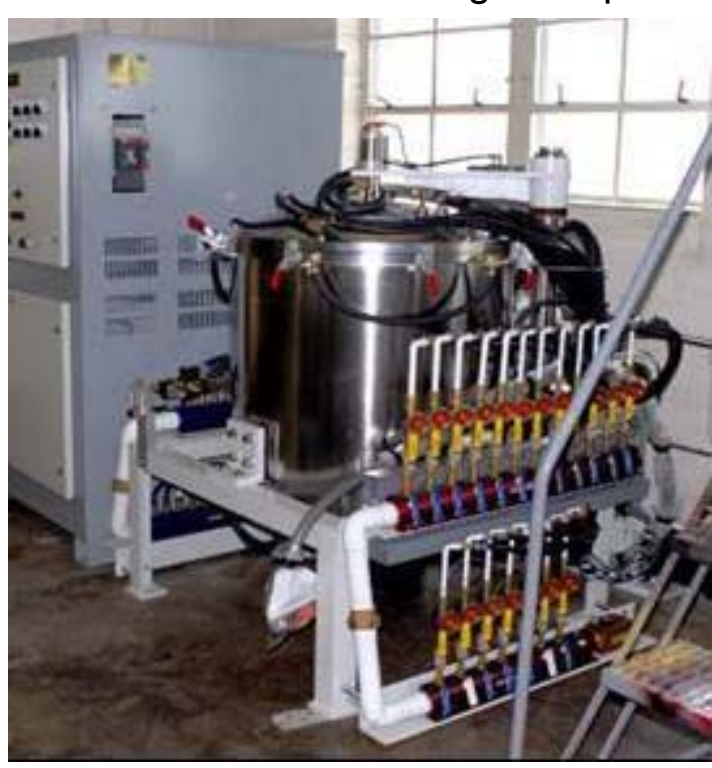

MSFC High Temperature Furnace. Licensed for depleted uranium

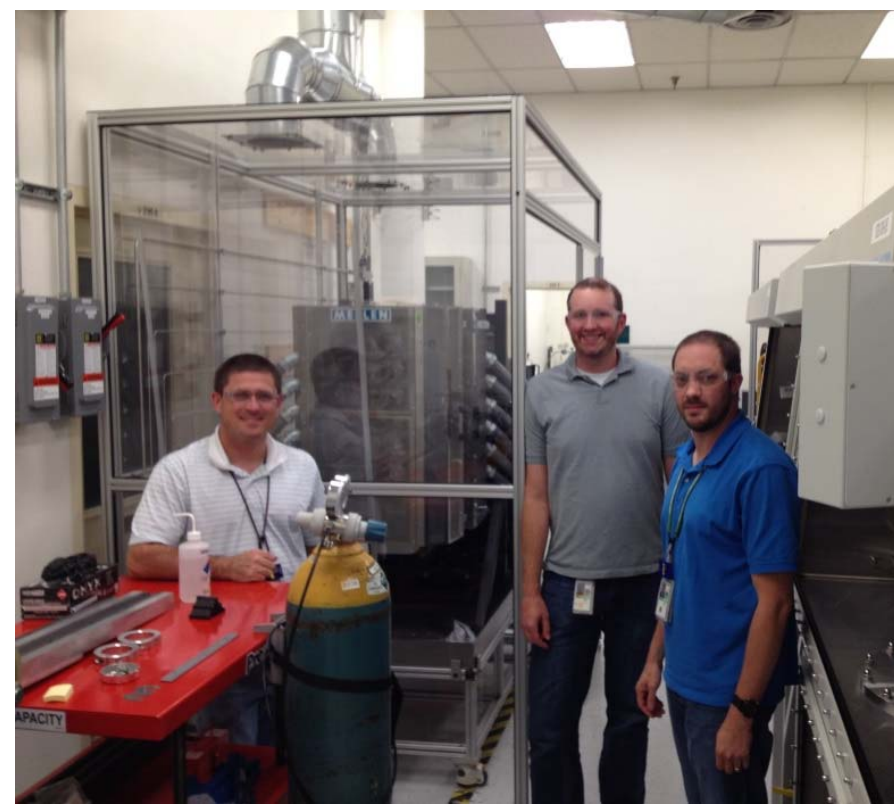

ORNL Fuels Dev. Team from left to right: Jim Miller, Brian Jolly, Mike Trammel. ORNL multi-zone coating furnace shown in background.
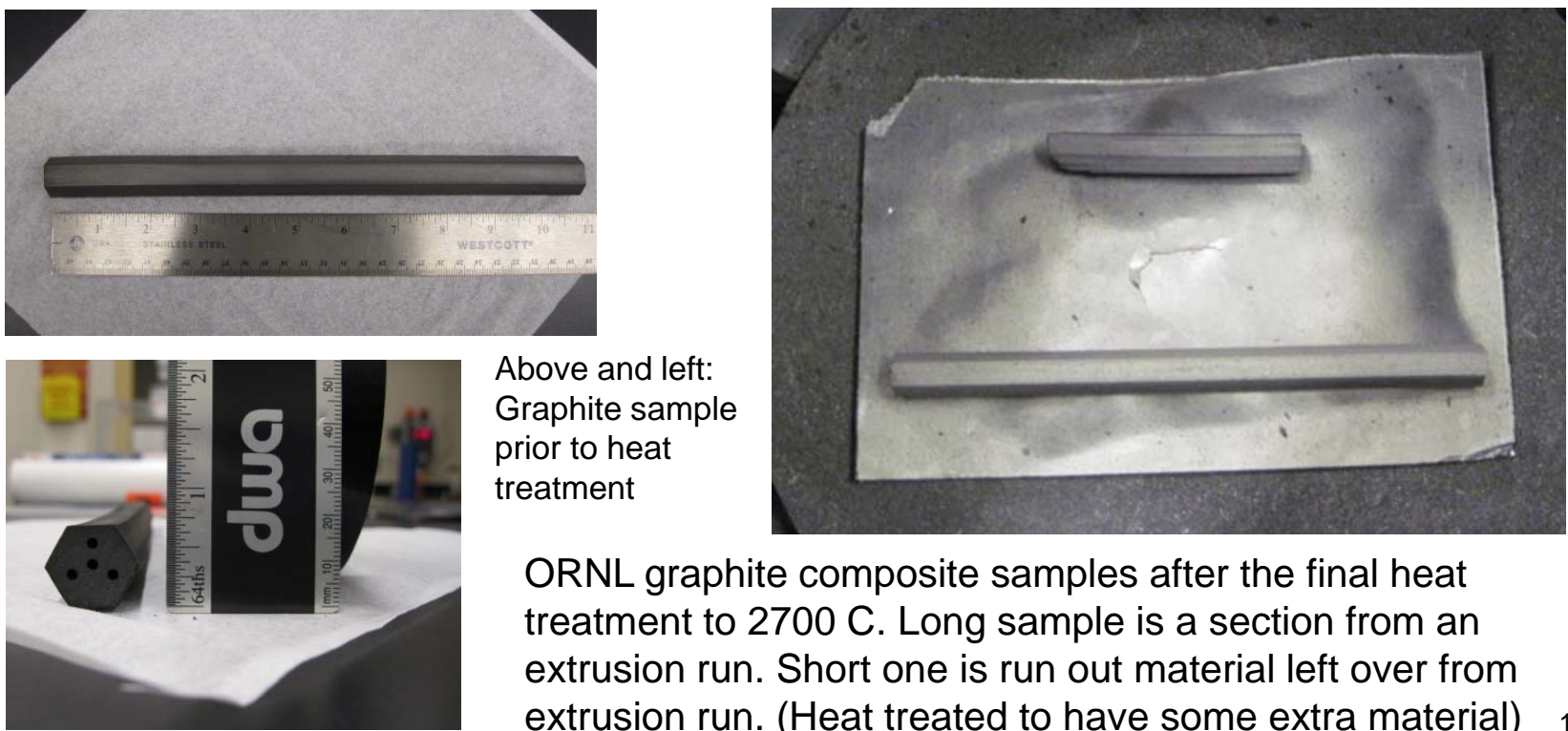

Above and left: Graphite sample prior to heat treatment

ORNL graphite composite samples after the final heat treatment to $2700 \mathrm{C}$. Long sample is a section from an extrusion run. Short one is run out material left over from extrusion run. (Heat treated to have some extra material) 


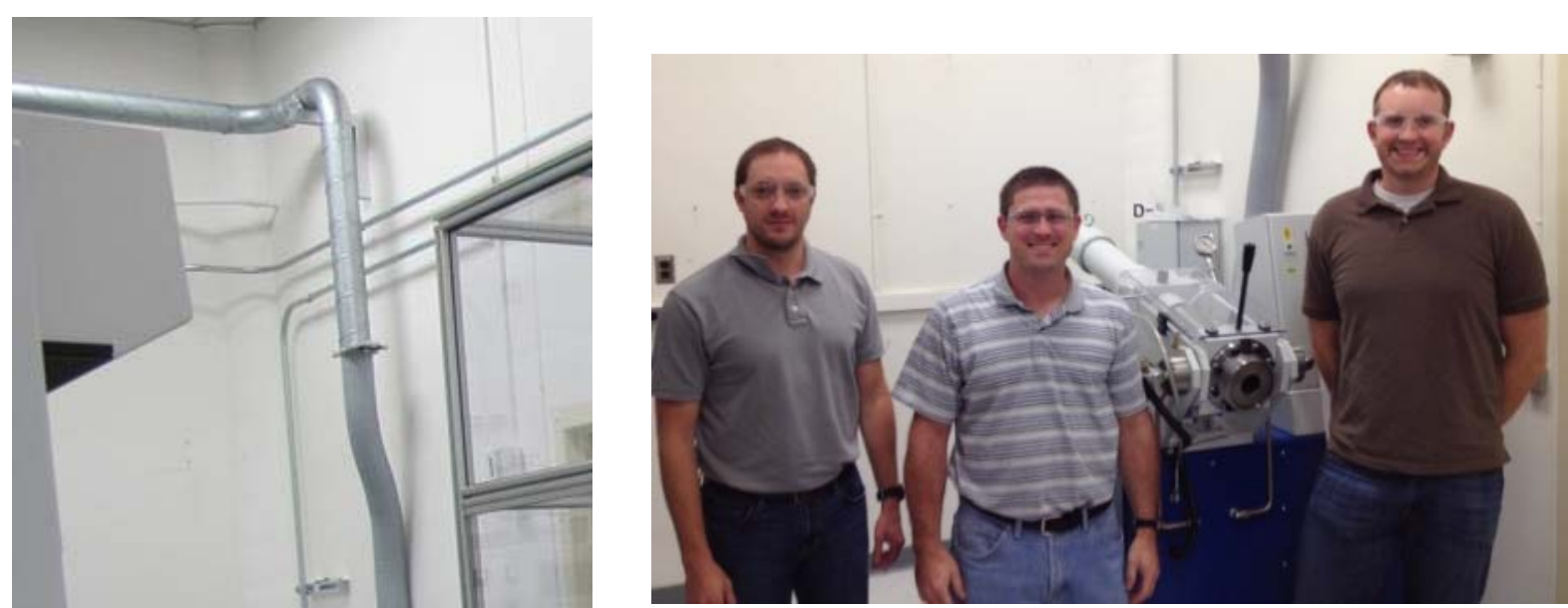

Above: Members of Oak Ridge National Laboratory fuels team with the graphite extruder; Left: Graphite extruder with vent lines installed for DU capability

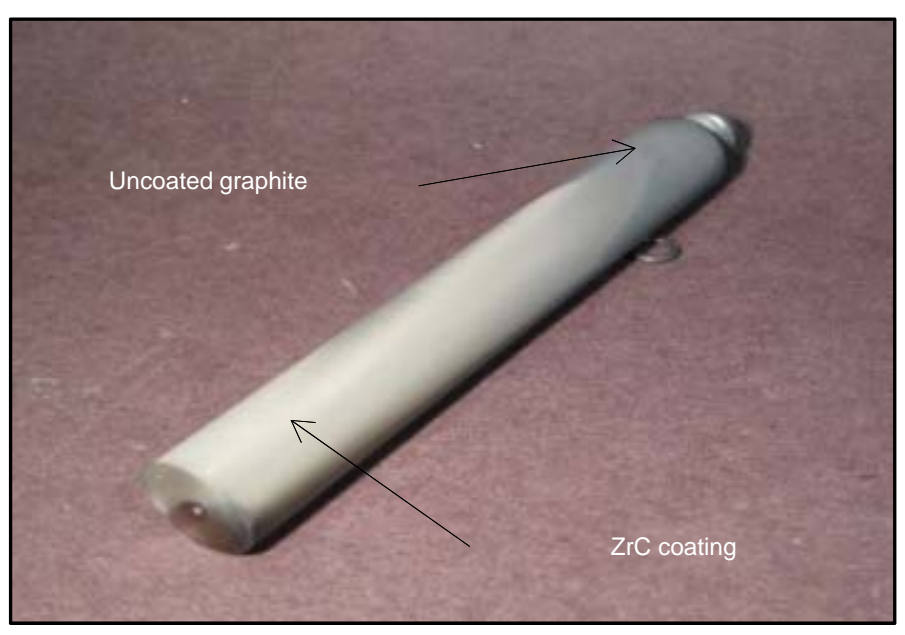

Above: Test Piece highlighting ZrC Coating Right: Coating primarily on external surface
Right: Layoff

base I

Graphite insert
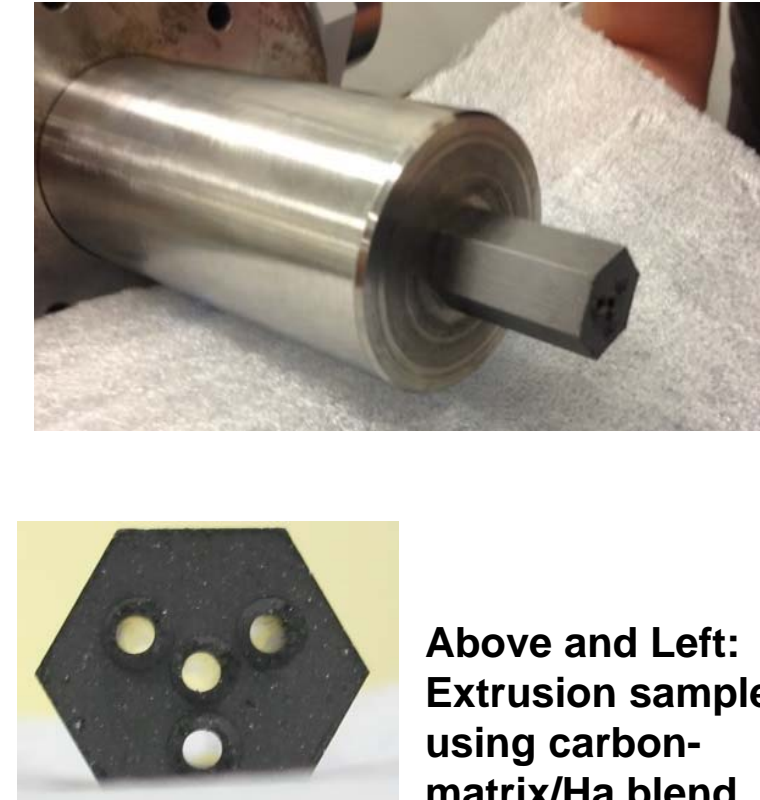

Above and Left: Extrusion samples using carbonmatrix/Ha blend .75" across flats, .125" coolant channels
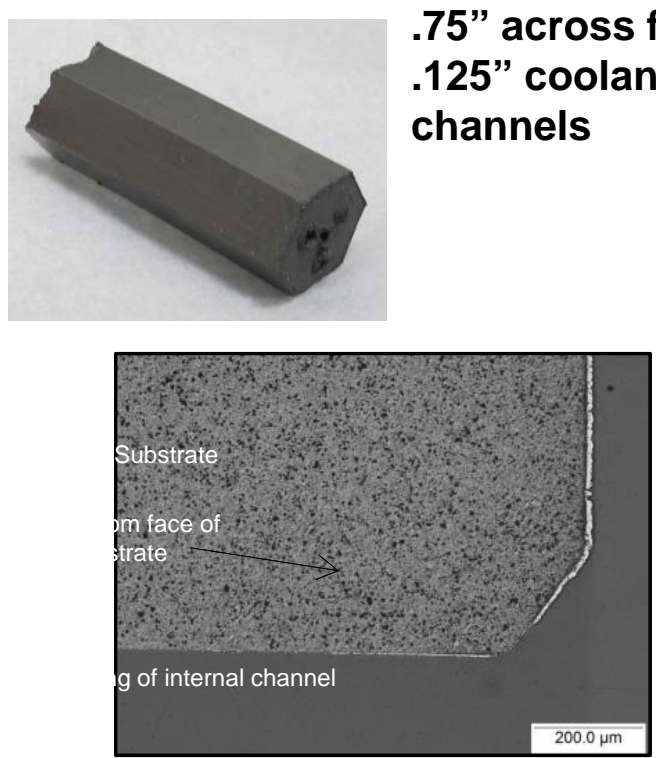


\section{ORNL Graphite Composite Development}

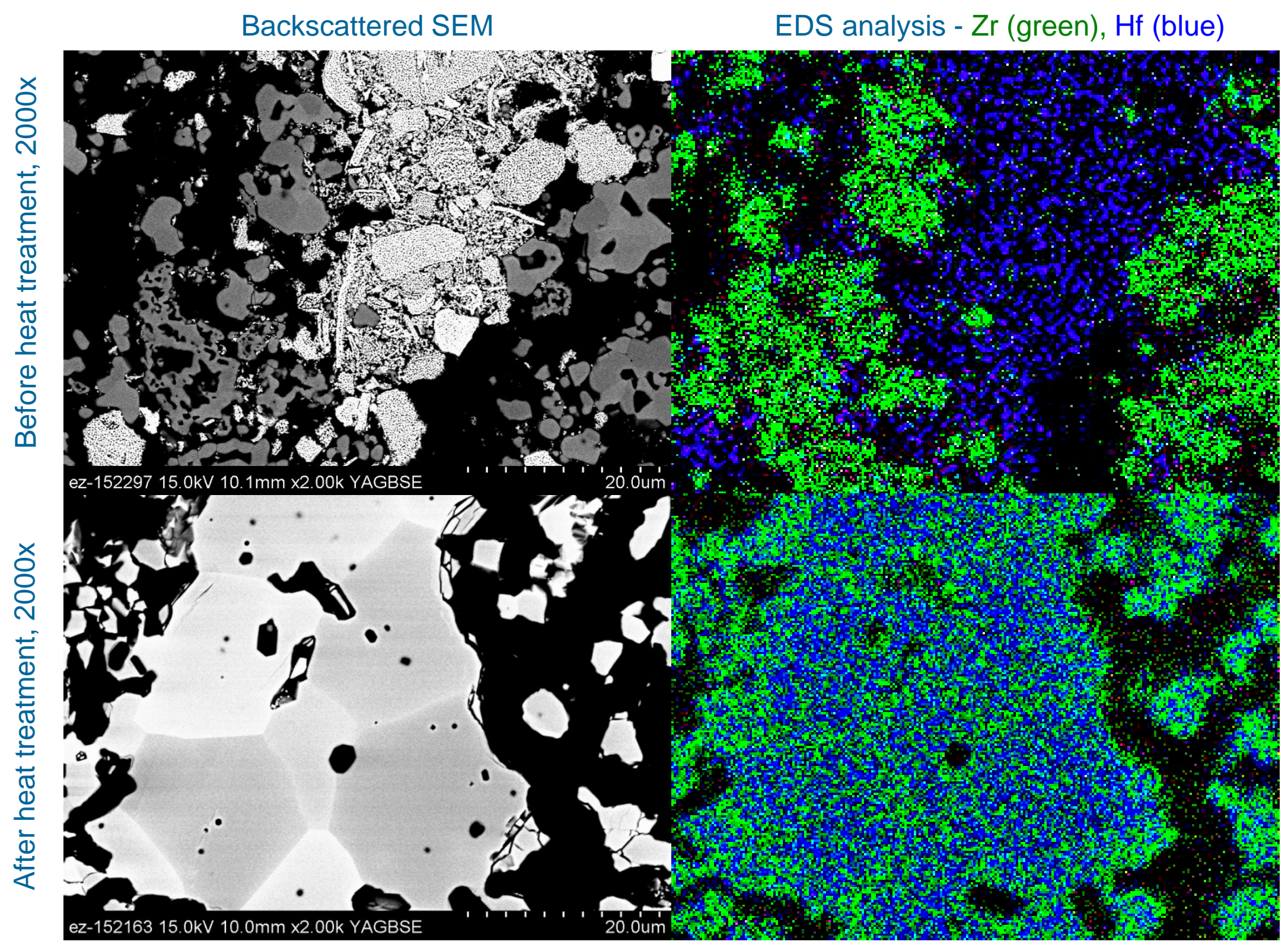




\section{Other Milestones: Testing in NTREES}
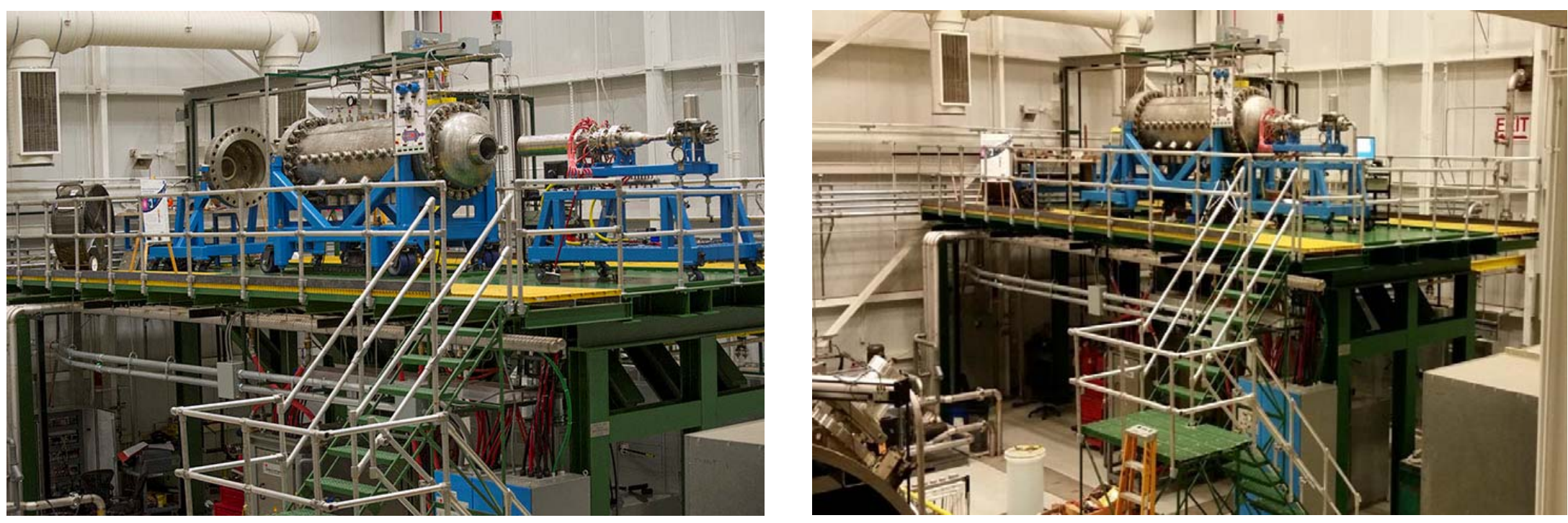

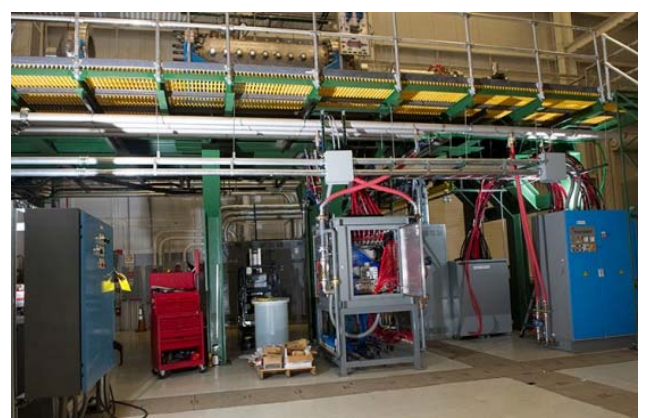

1.2 MW induction heater and DAQ system

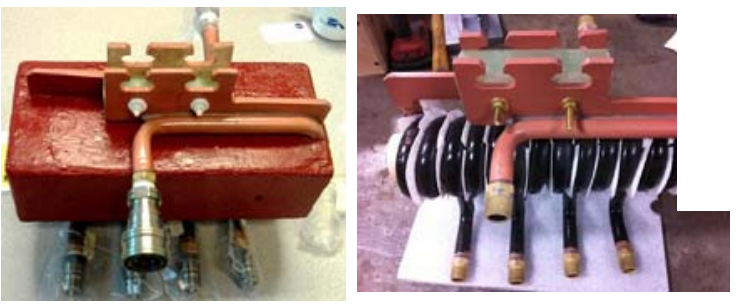

Induction coil with and without insulation
Above left \& right: NTREES in preparation for graphite FE testing

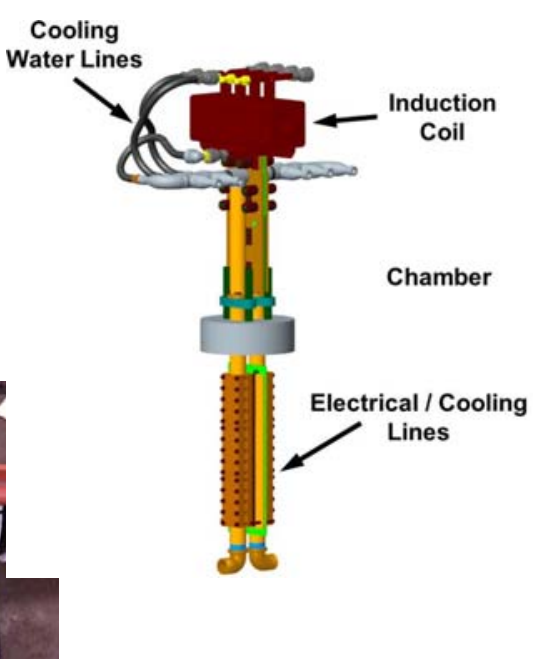

- NTREES has been modified to allow much higher power operation - achieved $>200 \mathrm{~kW}$

- Check out testing uncovered design deficiencies which limited the power that could be applied to test elements

- Design deficiencies have been corrected

- Modifications to coils needed prior to very high power testing - pursuing designs to allow greater test fidelity

- NTREES on track to be ready for testing fuel elements with prototypic depleted uranium loading in March, 2015 

(NTREES)

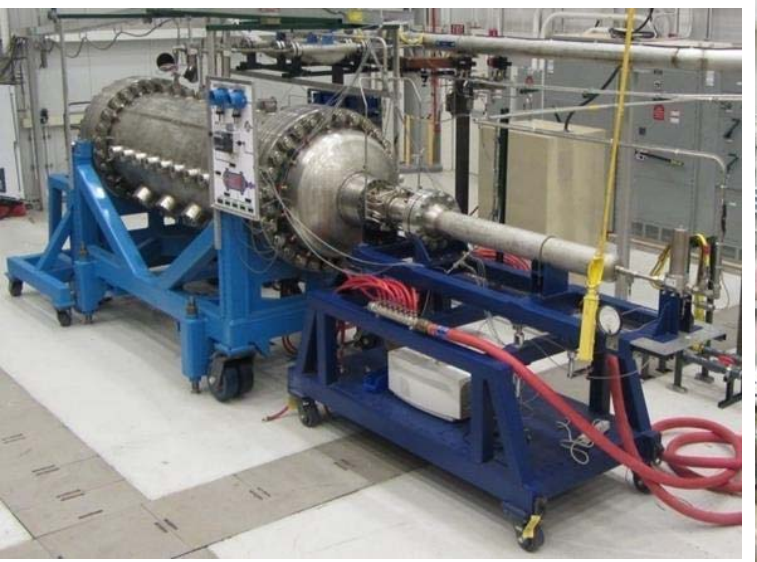

NTREES Phase 1 50kW (2011)

\section{General Description:}

- Water cooled ASME coded test vessel rated for 1100 psi

- $\mathrm{GN}_{2}$ (facility) and $\mathrm{GH}_{2}$ (trailer) gas supply systems

- Vent system (combined $\mathrm{GN}_{2} / \mathrm{GH}_{2}$ flow)

- $1.2 \mathrm{MW}$ RF power supply with new inductive coil

- Water cooling system (test chamber, exhaust mixer and RF system)

- Control \& Data Acquisition implemented via LabVIEW program

- Extensive $\mathrm{H}_{2}$ leak detection system and $\mathrm{O}_{2}$ monitoring system

- Data acquisition system consists of a pyrometer suite for axial temperature measurements and a mass spectrometer

- "Fail Safe" design

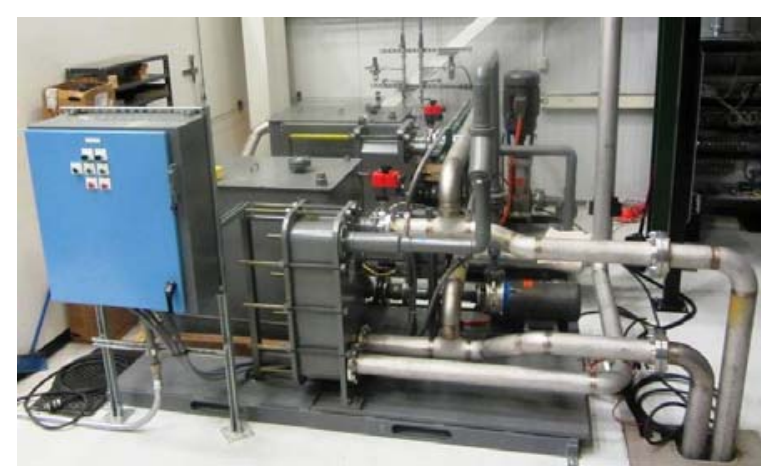

New Cooling Water System now provides 2 separate systems that cool induction coil and power feedthrough, induction heater and $\mathrm{H}_{2} \mathrm{~N}_{2}$ mixer respectively
New Coil is Heavily Insulated and Rugged

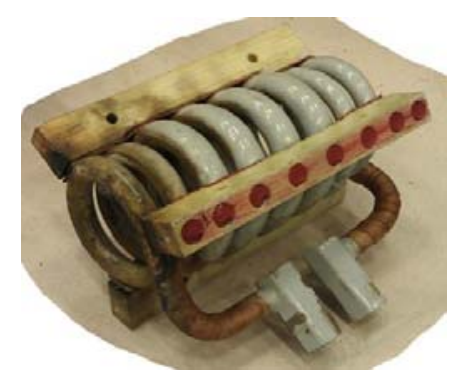

Old Coil was Somewhat Fragile Uninsulated and

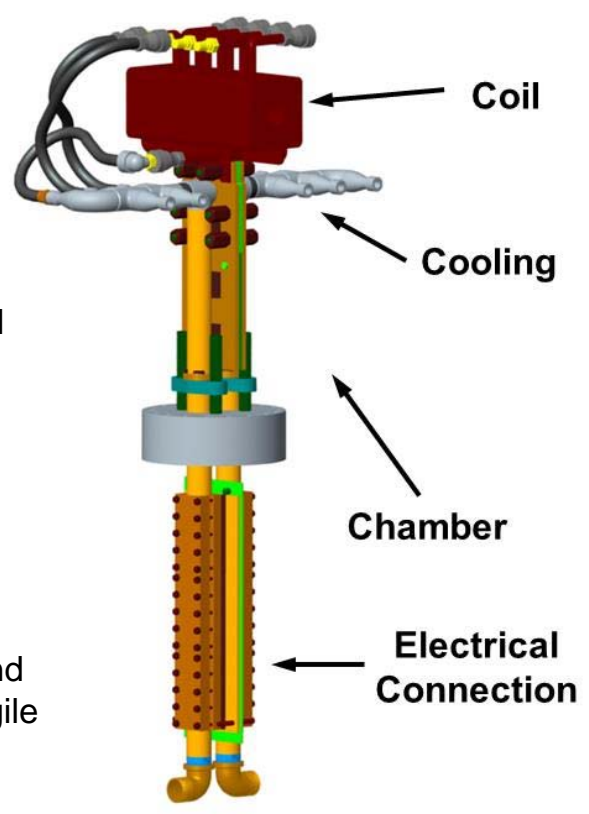

Coil and Feedthrough Assembly 


\section{Other Considerations}

60 years since the start of the Rover I NERVA program

NTP programs typically cancelled because mission is cancelled, not because of insurmountable technical or programmatic issues

Programmatic constraints, technical capabilities, available facilities, mission needs, etc. all continually change

Need to devise an optimal approach to developing a $21^{\text {st }}$ century NTP system

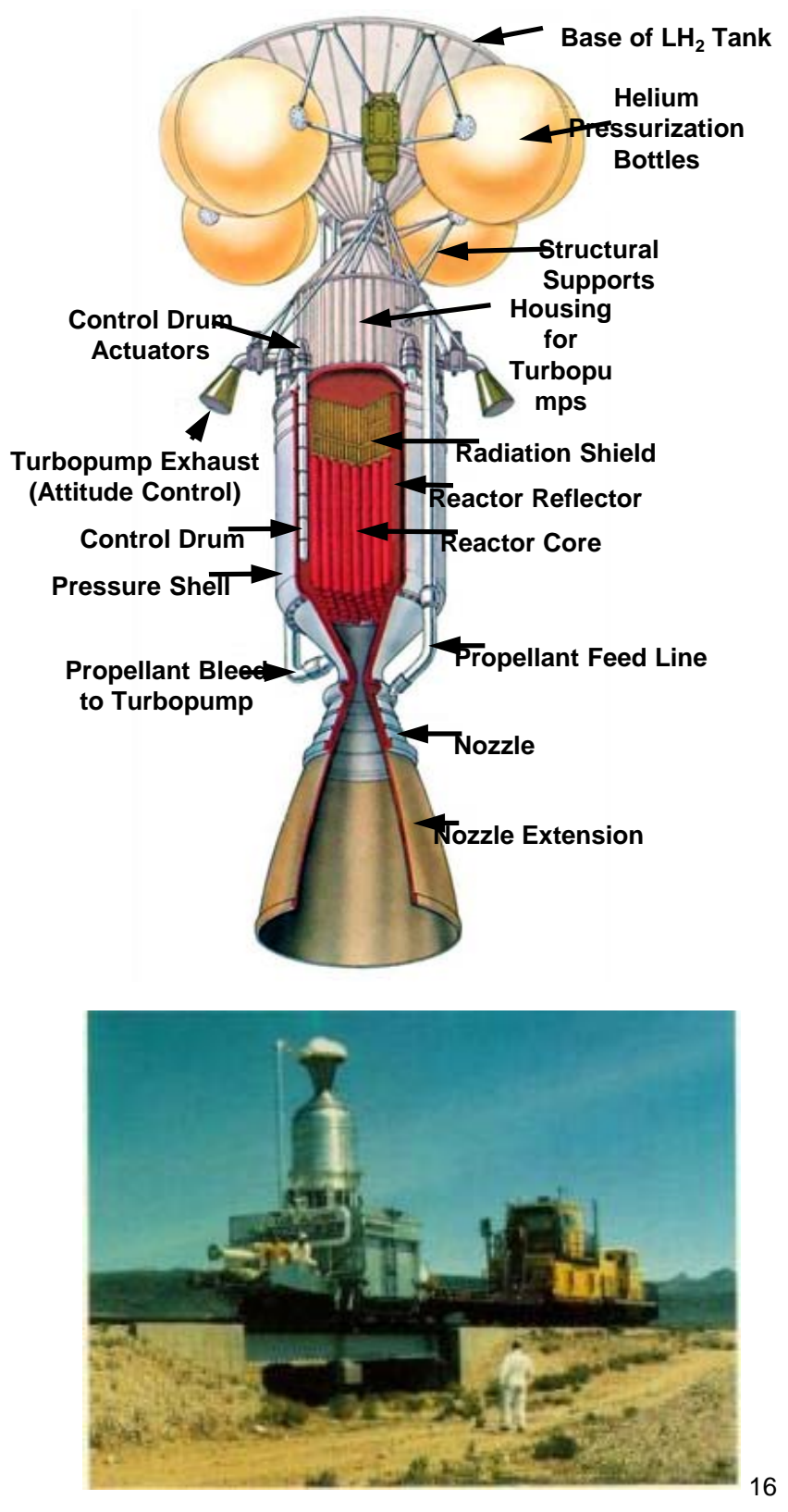




\section{Other Considerations}

\section{Options Have Changed}

Since 1955

Tremendous advances in computational capabilities (nuclear and non-nuclear).

Increased regulation and cost associated with nuclear operations and safeguards.

Extensive development of non-nuclear engine components. Extensive experience with various types of nuclear reactors.

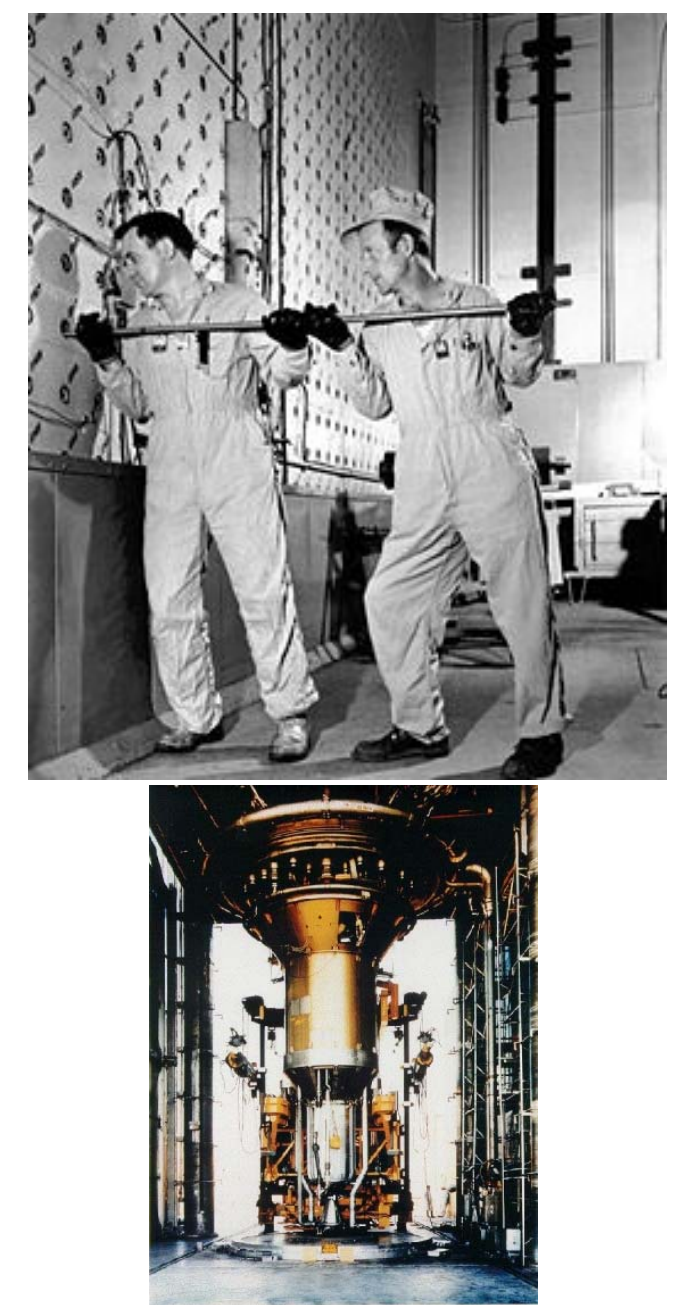

Recent successes in "space nuclear" public outreach (Mars Science Lab).

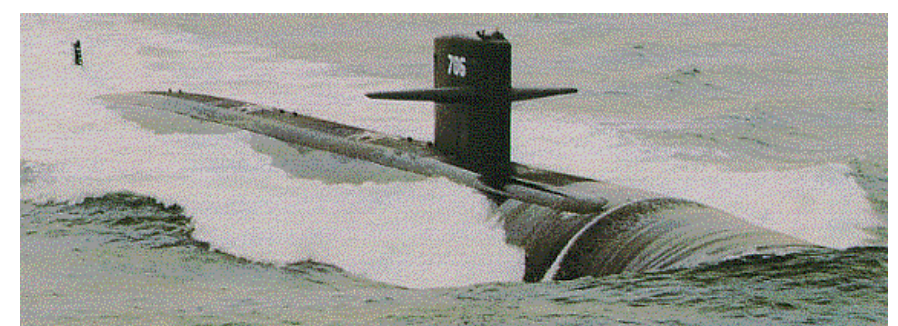




\section{Other Considerations}

Many Decisions will Affect Long-Term

Affordability and Viability of any Potential NTP

Development Program

- Balance between computational and experimental work.

- Flight qualification strategy / human rating.

- Low-enriched uranium vs highly-enriched uranium.

- Unscrubbed, scrubbed, or fully contained exhaust during ground testing.

- Choice of facility for any required testing (i.e. NCERC, NASA center, industry, etc.)

- Numerous others! 
HEOMD's AES Nuclear Thermal Propulsion (NTP) project is making significant progress. First of four FY 2015 milestones achieved this month.

Safety is the highest priority for NTP (as with other space systems). After safety comes affordability.

No centralized capability for developing, qualifying, and utilizing an NTP system. Will require a strong, closely integrated team.

Tremendous potential benefits from NTP and other space fission systems. No fundamental reason these systems cannot be developed and utilized in a safe, affordable fashion. 